\title{
ZEBRAFISH NEUROMAST HAIR CELL NUCLEI ARE LABELED IN VIVO BY UPTAKE OF MONOMERIC CYANINE DYES
}

\author{
Glen MacDonald*, David W. Raible**, Edwin W Rubel* \\ *Otolaryngology-HNS, Virginia Merrill Bloedel Hearing Research Center, Box 357923, University \\ of Washington, Seattle, WA 98195, USA \\ **Dept.Biological Structure, Box 357923, University of Washington, Seattle, WA 98195, USA
}

Hair cells are mechanosensory receptors that convert mechanical movement into neural activity. They are found in the inner ear sensory epithelia of vertebrates and in the lateral line neuromast organs of fish. Zebrafish have become a model for discovery of genes involved in development and regeneration of organ systems. We have begun to use this model to study hair cell death and regeneration [1]. To this end, we have sought methods to specifically label hair cells in vivo. The potentiometric dye DASPEI labels mitochondria in vivo with a pronounced affinity to neuromast hair cells [1]. However, DASPEI suffers from a broad emission spectrum and is not persistent. Some membrane permeant DNA dyes, such as Syto 24, preferentially label the nuclei of hair cells, but also label other cell types in a time dependent manner. This abstract reports the specific labeling of neuromast hair cells in vivo by monomeric cyanine dyes.

Zebrafish larvae, age E5-E6, were incubated with the monomeric cyanine dyes, Yo-Pro-1 and ToPro-3, or with Syto 24 (Molecular Probes, Eugene, OR). Cellular specificity was assessed by double-labeling with 1.3 mM DASPEI (Molecular Probes). Fish were imaged with a Bio-Rad MRC1024 laser scanning confocal microscope system coupled to a Nikon Diaphot 300 inverted microscope. Yo-Pro-1 and Syto 24 were excited at $488 \mathrm{~nm}$ and imaged with a 522DF35 emission filter, To-Pro-3 was excited at $647 \mathrm{~nm}$ and imaged with a 680DF50 emission filter, DASPEI was excited at $488 \mathrm{~nm}$ and its emissions collected with both a 522DF35 and a 605DF32 filter.

The cyanine dyes and Syto 24 brilliantly labeled neuromast hair cell nuclei and persisted for at least 48 hours. However, To-Pro-3 and Yo-pro-1 were restricted solely to hair cells, whereas Syto 24 also weakly labeled the surrounding support cells and scattered epithelial cells. Dye incubation up to 2 hours did not alter the expression of cyanine label but increased the extent of cells labeled by Syto 24. Yo-Pro-1 and Syto 24 labeling in hair cell nuclei could be observed by widefield microscopy after only $15 \mathrm{~min}$. incubation with $.5 \mu \mathrm{M}$ dye. However, confocal imaging for Yo-Pro-1 and ToPro-3 was greatly improved by using a concentration $2 \mu \mathrm{M}$ with a $30 \mathrm{~min}$. incubation.

Monomeric cyanine dyes are normally regarded as membrane impermeant due to their doubly cationic charge, but are known enter certain cells through ATP-regulated cationic channels[2][3]. Our observations suggest that zebrafish hair cells may possess some form of ATP-regulated channels. The presence of such channels and their possible role hair cell development will be a matter of future work [4]. 
[1] J.A. Harris et al., Assoc. Res. Otolarygology, 25 (2002)151 (abstract).

[2] T. Idziorek et al.,J Immunol. Meth. 185 (1995) 249.

[3] A. Surprenant et al., Science 272 (1996) 735.

[4] This work was support by the National Institute of Deafness and Communication Disorders.

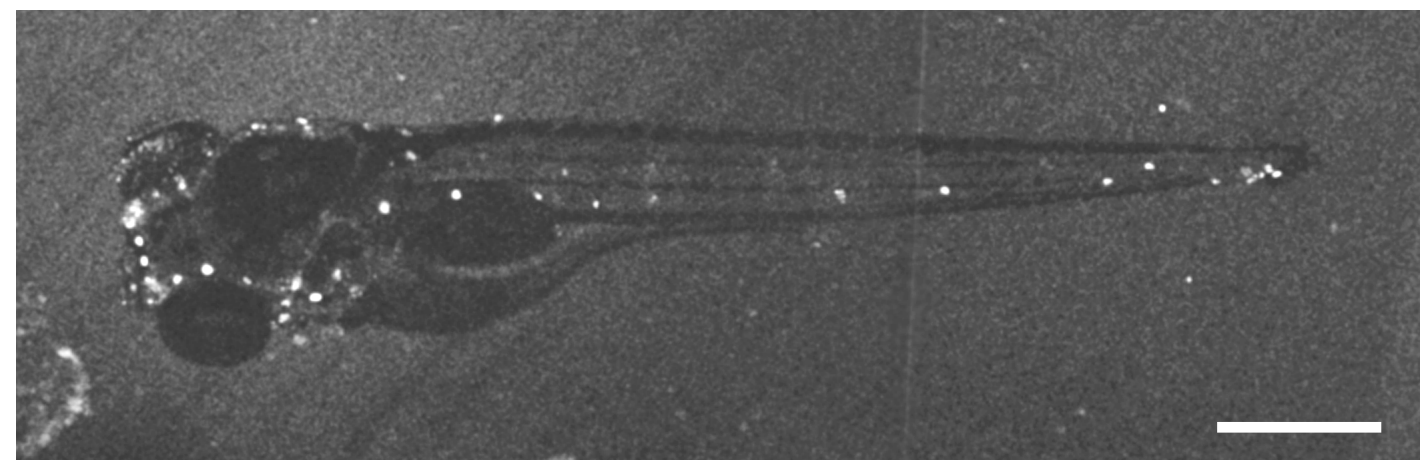

FIGURE 1. An E6 zebrafish larva labeled with Yo-Pro-1 displays bright neuromasts over its head and along the trunk. Scale bar $=500 \mu \mathrm{m}$.
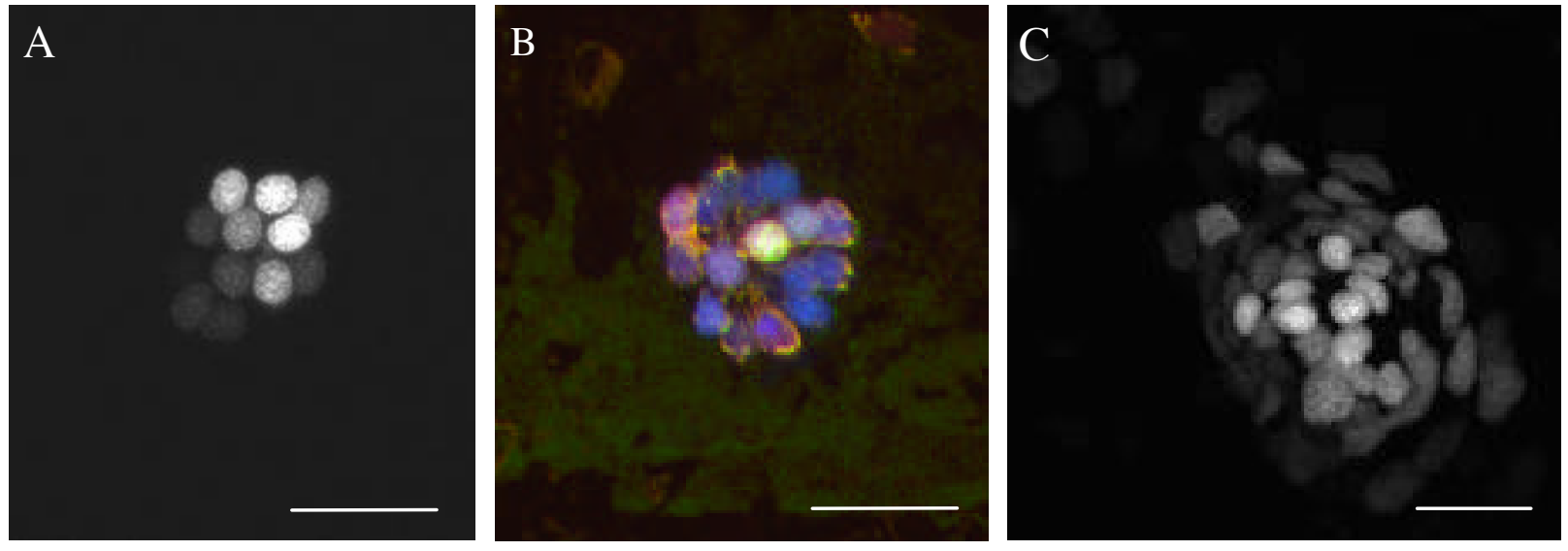

FIGURE 2A. Hair cells from trunk neuromasts with nuclei labeled by Yo-Pro-1,2 $\mu \mathrm{M}, 30 \mathrm{~min}$.

FIGURE 2B. A trunk neuromast double-labeled with To-Pro-3, $2 \mu \mathrm{M}, 2 \mathrm{hrs}$., and DASPEI, $1.3 \mathrm{mM}$, 15 min. The yellow mitochondria wrap the nuclei and extend toward the hair cell apices.

FIGURE 2C. A trunk neuromast labeled with Syto24, $2 \mu \mathrm{M}, 2$ hrs. Note the brighter, round hair cell nuclei surrounded by elliptical to kidney-shaped support cell nuclei and a few large epithelial nuclei. Scale bars $=20 \mu \mathrm{m}$. 